\title{
Diversos modos de pensar o conceito de substância química na história da ciência e sua visão relacional
}

\author{
Many ways of thinking the concept of chemical substance \\ in science history and its relational view
}

João Roberto Ratis Tenório da Silva ${ }^{1}$

\begin{abstract}
Resumo: O conceito de substância é considerado importante, pois serve de base para a aprendizagem de outros conteúdos. Em seu desenvolvimento histórico, encontram-se formas de falar relacionadas com modos de pensar, os quais foram organizados em cinco zonas de um perfil conceitual: generalista, essencialista (utilitarista/pragmática), substancialista, racionalista e relacional. Concepções da zona relacional são pouco discutidas em sala de aula. A discussão da visão relacional é importante, pois permite que alunos tenham consciência de certos comportamentos das substâncias. Assim, o objetivo deste artigo foi apresentar um breve relato do desenvolvimento histórico do conceito de substância química, contemplando as cinco zonas do perfil conceitual, destacando as concepções da zona relacional. Apontam-se diretrizes sobre a necessidade da ampla discussão deste conceito em sala de aula, além da necessidade de pesquisas sobre métodos de ensino que promovam tais discussões, levando em consideração, além da visão relacional, as ideias das demais zonas do perfil conceitual.
\end{abstract}

Palavras-chave: Ensino de química. Substância química. Conceito.

\begin{abstract}
The concept of substance is considered important, because it is the basis for learning other content. In its historical development, we find ways of speaking related to ways of thinking, which are organized into five zones of a conceptual profile: generalist, essentialist (utilitarist/pragmatic), substantialist, rationalist and relational. Concepts of the relational zone are rarely discussed in the classroom. The relational view discussion is important because it allows students to become aware of certain behaviors of substances. This article aims to provide a brief account of the historical development of the concept of substance, covering five zones of the conceptual profile, highlighting the concepts of the relational zone. It points not only to the need for extensive discussion of this concept in classroom but also to the need for research on teaching methods that promote these discussions, taking into account both, the relational view and the ideas of other zones of the conceptual profile.
\end{abstract}

Keywords: Chemistry teaching. Chemical substance. Concept.

\footnotetext{
${ }^{1}$ Universidade Federal Pernambuco (UFPE), Caruaru, PE, Brasil.

Orcid: <http://orcid.org/0000-0001-9682-8889>. E-mail: <joaoratistenorio@gmail.com>.
} 


\section{Introdução}

O conceito de substância é considerado um dos mais importantes na Química, sendo a sua compreensão importante para a estruturação de diversos outros conceitos, como o de elemento, mistura e reações químicas (OLIVEIRA, 1995; SILVEIRA, 2003; SILVA; AMARAL, 2013). Ao longo da história, é possível identificar diversas formas de falar este conceito, as quais estão associadas com diferentes modos de pensar, demonstrando que sua evolução se deu a partir da passagem por vários tipos de concepções. Esses diversos modos de pensar podem emergir em diversos contextos atuais, no discurso de alunos e professores de Química, visto a proximidade de concepções informais/alternativas com ideias científicas que já foram válidas em algum período histórico (POZO; CRESPO, 1998). Na literatura é possível encontrar diversos levantamentos de concepções informais/alternativas do conceito de substância, tais como os encontrados em Araújo, Silva e Tunes (1994), Johnson (2000, 2002) e Vogelezang (1987), entre outros. Essas concepções, quando organizadas a partir de compromissos epistemológicos, ontológicos e axiológicos, podem constituir zonas de um perfil conceitual. A teoria do perfil conceitual (MORTIMER; EL-HANI, 2014) explica a possibilidade de um único sujeito pensar um conceito de vários modos diferentes, usando formas de falar (associadas aos modos de pensar) em contextos específicos, possuindo um perfil conceitual que lhe é próprio, construído ao longo da vida por meio de suas diferentes vivências e experiências. Dessa forma, considera-se que um sujeito pode apresentar diversas concepções sobre o conceito de substância, desde as mais simples e intuitivas às mais complexas, e usá-las de acordo com o sentido que ele atribui em determinados contextos ou situações. O perfil conceitual de substância, proposto por Silva e Amaral (2013), apresenta cinco zonas: generalista, essencialista, substancialista, racionalista e relacional. Abaixo, as cinco zonas são apresentadas brevemente, com uma proposta de reformulação na zona essencialista, segundo os compromissos epistemológicos destacados por Silva e Amaral (2013), passando a se chamar zona utilitarista/pragmática.

\section{Zona Generalista}

Esta zona está relacionada com uma perspectiva generalista, em que são visualizadas totalidades em detrimento das partes, ou são buscados princípios universais para a compreensão de todas as coisas. Com relação ao conceito de substância, essa zona diz respeito às ideias em que qualquer objeto é tratado como substância, sendo a compreensão sobre os materiais pautada a partir de generalidades ou princípios gerais. Formas de falar relacionadas a essa zona são comuns em situações do cotidiano, em que, geralmente, qualquer material pode ser classificado como uma substância ou compreendido a partir de uma substância única à qual está associado. Dessa forma, em contextos do senso comum, é possível observar pessoas que consideram misturas como detergente, leite ou água mineral como substâncias, independentemente desses materiais serem formados por diversos componentes químicos. 


\section{Zona Utilitarista/Pragmática}

Nessa zona, a compreensão de substância está associada à aplicação ou utilidade que ela pode ter, principalmente para os seres humanos. Ela inclui concepções em que o sujeito compreende as substâncias a partir de atributos que são importantes para a manutenção da vida, ou que têm utilidade prática podendo gerar benefícios ou malefícios. Assim, em algumas situações, pessoas ressaltam a importância e influência das mais diversas substâncias, encontradas nos materiais ou produtos naturais, para a saúde. Por exemplo, recomenda-se a ingestão de alimentos que contêm proteína, tais como leite, queijo e demais alimentos de origem animal, por causa do benefício das proteínas na manutenção do corpo e como fonte de energia para atividades diárias, quando carboidratos e lipídios são insuficientes. Também é comum recomendar o uso de medicamentos, produtos fitoterápicos ou suplementos alimentares para suprir necessidades do organismo, por exemplo, ao falar "você precisa de ferro para ficar forte!". A menção ao ferro, neste caso, não necessariamente implica na visualização de uma substância, no sentido químico, mas está associada ao benefício de algum produto ou material em uma situação específica. Outra forma de falar, também associada a essa zona, é a justificativa para ingestão de determinados tipos de alimentos, que contêm nutrientes importantes para a saúde, porque tais alimentos são substanciais ou apresentam "substância" (ou "sustança", no sentido que são fortes e fornecem energia).

\section{Zona substancialista}

Nessa zona, o sujeito começa a expressar ideias científicas sobre o conceito de substância química, tendo noção da existência de diferentes compostos, classificações e propriedades. Porém, nas formas de falar, observa-se que há uma tendência em considerar que as propriedades físicas e químicas das substâncias também se manifestam em seus constituintes (átomos e moléculas). É um modo de pensar encontrado disperso na linguagem química, sendo possível identificar na fala de professores, alunos e em livros de Química. A ideia substancializada do conceito de calor (AMARAL; MORTIMER, 2001) e de energia (SIMÕES NETO, 2016) são exemplos de como esse modo de pensar é usado na linguagem química, quando frases do tipo "a energia é transferida" ou "calor é cedido para o ambiente" são usadas em sala de aula ou livros didáticos. Mortimer (1997) afirma que livros didáticos de Bioquímica, por exemplo, explicam de forma substancialista que energia é liberada quando uma ligação P-O é quebrada numa molécula de ATP. Além disso, essa zona também é encontrada em definições para o conceito de molécula, encontradas em handbooks e dicionários, quando afirmam que a molécula se trata da "menor quantidade unitária de matéria que pode existir por si mesma e que retém todas as propriedades da substância original” (MORTIMER, 1997, p. 203). Essa definição é substancialista no sentido em que as moléculas não retêm todas as propriedades da substância original. As propriedades são relativas às substâncias e não aos seus constituintes individuais (átomos e/ou moléculas). Porém, devido a essa presença em contextos científicos, Mortimer (1997, p. 203) considera que "é uma zona importante do perfil para a própria ciência, uma vez que seu uso automático e quase inconsciente na linguagem química pode produzir confusão, levando os químicos e, principalmente, os estudantes de química, a cometerem erros". 


\section{Zona Racionalista}

Nessa zona, segundo Silva e Amaral (2013), encontram-se concepções mais próximas daquelas trabalhadas no contexto científico. Geralmente, são ideias científicas construídas a partir do século XVII, fazendo parte do que se pode chamar de Química Clássica. Essa zona apresenta dois modos de pensar, associados a formas de falar:

- Visão macroscópica: o sujeito compreende a existência das diversas substâncias a partir da identificação de propriedades físicas e químicas, que se manifestam macroscopicamente. Essas propriedades têm a função de identificar as substâncias, sendo próprias a elas. Por exemplo, a substância água é caracterizada por ter a temperatura de ebulição de $100^{\circ} \mathrm{C}$; ou as substâncias metálicas são caracterizadas por apresentarem brilho, maleabilidade e dureza;

- Visão microscópica: além da identificação e caracterização das substâncias a partir de suas propriedades, há consciência sobre as diversas classificações (substâncias simples, composta, orgânica, inorgânica, etc) a partir do conhecimento da composição dos materiais e das substâncias que os compõem. Assim, o sujeito tem o conhecimento de que o ar atmosférico, por exemplo, é composto por diversas substâncias gasosas simples e compostas; ou da diferenciação de substâncias orgânicas e inorgânicas pela presença de carbono e hidrogênio em certas moléculas.

\section{Zona Relacional}

De acordo com Silva e Amaral (2013), nessa zona o conceito de substância é considerado como um modelo teórico para explicação do comportamento da matéria, sendo sua existência no mundo real considerada como um mito (OLIVEIRA, 1995). Assim, a ideia da existência de substâncias com 100\% de pureza, com propriedades físico-químicas bem definidas é considerada como uma aproximação teórica. Em um sistema, as moléculas de uma substância estão em constante interação com outras espécies no meio e com as vizinhanças, havendo uma constante troca energética (SILVA; AMARAL, 2013). Além disso, algumas de suas propriedades são relacionais (MORTIMER, 1997) e não bem definidas e constantes, tais como ponto de ebulição, acidez e basicidade e comportamento redox.

Acredita-se que uma análise da visão relacional do conceito de substância química pode contribuir para uma compreensão ampla deste conceito, visto que tal discussão não é explícita em livros didáticos de Química, inclusive aqueles de nível superior. Tal problema acaba por fazer com que o sujeito não tenha consciência de que as propriedades das substâncias e seu comportamento no ambiente são resultados de jogos relacionais entre as substâncias presentes em um sistema e suas vizinhanças, acabando por reforçar, dentro da sala de aula, ideias que são do senso comum, não adequadas dentro de um contexto científico.

Não é a intenção deste artigo afirmar que a visão relacional é "mais correta" do que as outras, visto o valor pragmático que cada modo de pensar o conceito de substância apresenta em determinados contextos (MORTIMER; EL-HANI, 2014). Porém, enfatiza-se a importância de uma ampla discussão da visão relacional em cursos de nível superior de Química, principalmente as licenciaturas, visto que futuros professores devem ter consciência das nuances do conceito de substância para não reforçar concepções informais/alternativas, como se observa na literatura (DINIZ JUNIOR; SILVA; AMARAL, 2015). 
Diante do exposto acima, o objetivo deste artigo é apresentar um breve relato do desenvolvimento histórico do conceito de substância, a partir de fontes da história da Ciência, contemplando as cinco zonas do perfil conceitual de substância apresentadas acima, destacando como tal desenvolvimento culminou na ideia de uma substância que, no mundo real, não apresenta um comportamento padrão (com todas as propriedades bem definidas, por exemplo) dentro da visão relacional.

É importante destacar que, mesmo levantando a necessidade de uma discussão sobre a visão relacional, os químicos usam, na maior parte das suas práticas, formas de falar que consideram as substâncias "puras" e com propriedades bem definidas. Pode-se observar a presença desses tipos de modos de pensar a partir de formas de falar presentes nos próprios livros didáticos de Química. Um exemplo disso está na apresentação do diagrama de fases da água em Atkins e Jones (2012, p. 340) em que os autores destacam a temperatura de ebulição da água em $100^{\circ} \mathrm{C}$, sendo essa característica em função de uma pureza de $100 \%$ da substância. A justificativa disso se dá por ser parte da cultura dos químicos considerar que diversas substâncias são puras, facilitando a interpretação de alguns processos, demonstrando o valor pragmático desse tipo de modo de pensar. O problema que se levanta nesse contexto é que nem toda situação no âmbito da Química permite tais considerações, sendo necessária uma reflexão sobre a visão relacional das substâncias para interpretação de alguns processos e fenômenos, sendo essa a justificativa do presente artigo.

\section{Diferentes modos de pensar o conceito de substância química na história}

Os diversos modos de pensar o conceito de substância química serão apresentados nos subitens a seguir, tomando como referência períodos históricos em que determinados tipos de concepções, referentes às zonas do perfil conceitual de substância, tiveram sua origem. No levantamento histórico apresentado, será possível observar que um determinado modo de pensar teve sua gênese em um dado momento histórico e suas ideias atravessaram longos períodos, estando presentes, inclusive, em diversos contextos atuais. Assim, as ideias das diferentes zonas do perfil conceitual coexistiram em diversos momentos na história da ciência e convivem ainda hoje em diversos contextos (MORTIMER; EL-HANI, 2014).

\section{Concepções generalistas}

Pode-se considerar que as primeiras noções sobre o conceito de substância tiveram sua gênese na Filosofia a partir de especulações sobre a origem do Universo, que fizeram surgir concepções acerca da natureza da matéria. Segundo Partington (1989), no contexto grego, as primeiras noções de substância tiveram origem na Escola Jônica. Os jônicos, ao especularem sobre a origem do Universo, conceberam princípios, os quais deram origem a todas as coisas no Universo. Para Tales de Mileto (639-546 a.C.), por exemplo, esse princípio permanente era a água, razão pela qual afirmava que a terra flutuava sobre ela. Para Anaximandro (610 - 547 a.C.), o aiperon era a substância que dava origem a todas as coisas. Anaxímenes (611-545 a.C.) 
concordava com a ideia de Anaximandro, porém, para ele, o aiperon era o "ar", o qual considerava como a substância primária. Mais à frente, Empédocles (490-435 a.C) introduziu a ideia dos quatro elementos - água, terra, ar e fogo (PARTINGTON, 1989). Esses princípios materiais eram entidades que estariam na composição de todos os corpos materiais que, segundo Aristóteles (384 a.C.-322 a.C.), poderiam sofrer transmutação, sendo suas qualidades primárias o quente, frio, úmido e seco (ARISTÓTELES, 1995).

Dessa forma, Aristóteles (1996, p. 142-143) se referiu à substância como Essência ou Ser (do grego ousia), atribuindo-lhe as seguintes características: (a) corpos simples, do que são exemplo a terra, o fogo, a água e similares; e, em geral, os corpos e as coisas deles compostas, animais e divinas, incluindo as partes destes. Todas essas coisas são chamadas substâncias porque não são predicadas de nenhum sujeito, embora tudo mais seja predicado delas; (b) aquilo que, estando presente em tais coisas, que não são predicadas de um sujeito, é a causa de seu ser, como por exemplo, no animal a alma é a causa de seu ser; (c) todas as partes presentes nas coisas que são definidoras e indicadoras de sua individualidade, e cuja supressão do todo, como por exemplo, segundo alguns, o plano. Alguns pensam que o número, em geral, também seja dessa natureza, sob o fundamento de que se ele fosse suprimido, nada existiria, sendo ele o que determina tudo; (d) a essência, cuja fórmula é a definição, também é chamada substância de cada coisa particular. Diante dessas características, pode-se sintetizar alguns atributos das substâncias apontados por Aristóteles:

- Imutável;

- Representa algo absoluto;

- Representa o Ser, ou seja, a individualidade de cada corpo;

- A existência das coisas depende da existência desta substância, ou seja, as coisas existem em função da substância;

- Não é predicada de nenhum sujeito, ou seja, é elementar (neste ponto percebe-se como os conceitos de elemento e substância se confundiam, não existindo uma diferença clara entre os dois);

- Pode ser material ou imaterial, porém sempre representando a essência de um corpo maior.

A ideia generalista, neste contexto, é concebida a partir da busca e da percepção de algo que pudesse ser considerado como um princípio geral, comum a todas as coisas presentes na Natureza. A ideia de que a água, fogo, terra e ar, sendo considerados corpos simples e materiais, estarem presentes em toda natureza, sugere que tais modos de pensar possuam uma característica generalista, estando presentes também em outros contextos e períodos históricos. O alquimista Paracelso - Philippus Aureolus Theophrastus Bombastus von Hohenheim (1493-1541) - pensou na existência de corpos os quais representavam princípios que estavam presentes nos corpos e explicavam alguns fenômenos, como a queima de materiais. Estes princípios eram o sal, o enxofre e o mercúrio. Segundo ele, o sal era o princípio da fixação e incombustibilidade, o mercúrio era o princípio da fusibilidade e volatilidade e o enxofre o princípio da inflameabilidade (PARTINGTON, 1989). Ainda segundo Paracelso, essas três substâncias juntas formavam a tria prima, e o sal, o enxofre e o mercúrio representavam o corpo a alma e o espírito, respectivamente (GOLDFARB, 2001). A ideia dos princípios (mercúrio-enxofre) também é atribuída ao alquimista árabe Jabir ibn Hayyan (721 d.C.-815 d.C.) (OKI, 2002). Segundo suas ideias, nessa teoria, todos os corpos seriam formados em diferentes proporções por dois princípios: 
Diversos modos de pensar o conceito de substância química ...

o enxofre, portador da propriedade combustibilidade, e o princípio mercúrio, carregador da "metalicidade".

\section{Concepções utilitaristas/pragmáticas}

Nas primeiras grandes civilizações, não se conhecia muito sobre a matéria, mas havia um grande interesse no uso de materiais para usufruto das comunidades que se formavam. $\mathrm{Na}$ Idade Antiga (4000 a.C. 500 d.C.), ainda que a relação com os materiais tivesse predominantemente esse caráter pragmático, a manipulação de materiais possibilitou que, ao longo dos anos, um grande número de substâncias químicas fosse conhecido, tais como, óxidos de cobre, ferro e zinco; alumínio, sulfatos de cobre e ferro; sulfitos de arsênico e mercúrio e produtos vegetais e animais. Assim, pode-se ressaltar que apesar de haver uma motivação pautada pelo uso e aplicação de produtos em atividades humanas, as técnicas desenvolvidas para manipulação foram despertando no ser humano a curiosidade em saber mais a respeito da natureza da matéria (PARTINGTON, 1989). Nesse sentido, verifica-se que uma visão mais utilitarista da matéria não excluiu a possibilidade de busca por uma compreensão mais aprofundada da sua natureza.

Os metais, em geral, eram amplamente utilizados por esses povos para a fabricação de diversos artefatos. A extração de substâncias era considerada uma tarefa sagrada (GOLDFARB, 2001), por isso a manipulação desses metais era feita em um contexto de misticismo e religiosidade.

Ideias utilitaristas/pragmáticas também aparecem na Idade Média e na Alquimia como um todo. Nessa época, percebe-se a tendência em considerar que alguns objetos são responsáveis pela manutenção da vida na Natureza. Acreditava-se, por exemplo, que os metais tinham a capacidade de gerar e manter a vida (LEICESTER, 1967; PARTINGTON, 1989). Pode-se observar o reflexo dessas ideias nas tentativas dos alquimistas em obter a matéria morta para, a partir dela, gerar vida. Neste processo o material "morto" deveria perder a maior parte de suas propriedades metálicas, se tornar preto e depois passar por um processo de clareamento até chegar à cor dourada (LEICESTER, 1967). A Pedra Filosofal adiantava esse processo de transmutação e toda a história da Alquimia (não só no Ocidente) tinha como um dos objetivos principais a busca desse poderoso material e do Elixir da Longa Vida, o qual, como o nome propõe, oferecia vida eterna a quem o usasse (GOLDFARB, 2001; LEICESTER, 1967; PARTINGTON, 1989, entre outros). É interessante apontar que o aprofundamento no conhecimento da matéria a partir do seu uso ou aplicação faz emergir a ideia de propriedade para determinados tipos de materiais, o que pode representar uma aproximação de um pensamento mais sistematizado sobre as relações entre a composição, ou componentes presentes em materiais e suas propriedades. Algumas substâncias se tornam importantes devido às propriedades que apresentam em determinadas situações e contextos.

\section{Concepções substancialistas}

Formas de falar relacionadas ao modo de pensar substancialista se encontram dispersas na linguagem química atual, sendo também encontradas em alguns períodos e contextos históricos. Segundo Bachelard (1996), o substancialismo se relaciona à explicação monótona das propriedades pela substância. Assim, se atribui às substâncias qualidades diversas, estando tais 
qualidades presentes no interior das próprias substâncias. Isso, segundo Oliveira (1995), fazia com que os alquimistas tentassem "abrir" as substâncias, na perspectiva de alcançar e desvendar qualidades ocultas.

Bachelard (1996) apresenta o exemplo do alquimista David Macbride, em sua obra Essais d'experiences (1766), em que o autor procura provar, por meio de experimentos de decomposição de substâncias de origem animal e vegetal, que o ar fixo (conhecido atualmente como gás carbônico) é o princípio de coesão e de unidade substancial dessas substâncias. Assim, Macbride considera que o ar fixo é uma espécie de vínculo entre as substâncias, fazendo com que elas fiquem coesas. Dessa forma, se teria acesso, também, à qualidade de fixação do ar fixo que lhe era atribuída.

Segundo Bachelard (1996), outro exemplo de tentativas de abrir as substâncias a fim de ter acesso à qualidade interior é encontrado nos trabalhos de Jean Le Pelletier, em sua obra $V$ Alkaest ou le dissolvam universel de Van Helmont. Révélé dans plusieurs traités qui en découvrent le secret, publicada no ano de 1704. Neste livro, Le Pelletier considerava o metal mercúrio muito bem fechado, sendo suas qualidades internas (ou ocultas) de difícil acesso, assim como o enxofre. Dessa forma, era necessário buscar uma chave para abrir tais substâncias. No mesmo século, Joachim Poleman, em seu livro Nouvelle lumière de Médecine du mistere du souffre des philosophes (1721), afirmava que apenas o azeite teria poder de dissolver naturalmente o enxofre e revirá-lo de dentro para fora e que isso foi possível com o cobre, sendo possível liberar a "alma" do metal (BACHELARD, 1996).

Mortimer (1997), ao propor um perfil conceitual para molécula, também identificou uma zona substancialista, quando o sujeito considera que fenômenos macroscópicos, tais como dilatar, fundir e ferver - ocorrem no interior das substâncias, ou seja, com os seus constituintes (átomos e moléculas). O autor apresenta alguns exemplos encontrados na Idade Média, como, por exemplo, o de Joseph Scaliger (1484-1558) que, ao interpretar as ideias filosóficas de Anáxagoras e Aristóteles sobre a composição da matéria, inferiu que maciez e aspereza são propriedades dos corpos presentes no minima (constituinte da matéria). Além disso, segundo Mortimer (1997), ele distinguia entre propriedades da matéria que dependiam dos minima, tais como maciez e aspereza, e outras que dependeriam da forma como os minima eram unidos, como a densidade, por exemplo. Esse tipo de concepção também é encontrado no pensamento de Lemery (1645-1715), em sua obra Cours de chymie, publicado no século XVII. Sendo um dos mais populares livros de química na época, usava a teoria corpuscular de Descartes, que afirmava que as propriedades da substância dependiam da forma de suas partículas. Além disso, Lemery atribuía as propriedades dos ácidos à forma pontiaguda de suas partículas constituintes (MORTIMER, 1997).

\section{Concepções racionalistas}

Robert Boyle (1627-1691), no século XVII, acreditava na teoria atômica e considerava que as combinações químicas se faziam entre partículas elementares, a partir de afinidades químicas. No século XVIII, a ideia da existência de substâncias elementares continuava perdendo força no contexto científico. Os métodos de laboratório passaram por vários avanços nesta época e a Química estava se separando da Alquimia com base no pensamento empírico.

Os estudos acerca dos gases contribuíram para as primeiras definições sobre o conceito de substância, agora, de fato, podendo ser chamada de substância química. Experimentos rea- 
lizados por Stephen Hales (1677-1761), por exemplo, sobre a determinação da quantidade de gases que se podia extrair de uma substância pelo calor (LEICESTER, 1967; PARTINGTON, 1989), contribuíram para o rompimento das ideias filosóficas, pois se mostrava que o ar não era uma substância elementar, mas sim uma mistura formada por diversos outros gases. Joseph Black (1728-1799) também realizou experimentos importantes, como a determinação do calor latente, reconhecendo, assim, que as substâncias possuíam capacidades diferentes de calor ou um calor específico (SILVA, 2011). Com seus experimentos, ele determinou a existência de um "ar" que estaria presente no carbonato básico de magnésio: o ar fixo. Este é o mesmo "ar silvestre" encontrado anteriormente por van Helmont (PARTINGTON, 1989) sendo chamado posteriormente de gás carbônico. Os experimentos realizados por Cavendish (1731-1810), Scheele (1742-1786) e Priestley (1733-1804) também foram relevantes nos estudos dos gases e determinação de propriedades de diversas substâncias. Cavendish publicou em 1766 um estudo sobre as propriedades do ar inflamável (hoje, conhecido como hidrogênio) e o ar fixo (PARTINGTON, 1989). Carl Wihelm Scheele determinou que o ar era composto por dois fluidos, diferentes um do outro. Estes foram chamados de Foul air e Fire air, que mais adiante foram nomeados de nitrogênio e oxigênio, respectivamente (PARTINGTON, 1989). Já Priestley isolou e caracterizou um grande número de gases, não se comparando a nenhum de seus contemporâneos. Gorri e Filho (2009) relatam que Priestley identificou e estudou as propriedades de doze diferentes tipos de "ares", que mais à frente foram identificados como: oxigênio, nitrogênio, óxido nítrico, dióxido de nitrogênio, óxido nitroso, dióxido de carbono, hidrogênio, monóxido de carbono, dióxido de enxofre, cloreto de hidrogênio, amônia e tetrafluoreto de silício.

Ainda no século XVIII, observa-se as contribuições dos trabalhos de Antoine Lavoisier (1743-1794). Segundo Paolloni (1980), Lavoisier completou os trabalhos de Black, Priestley e Cavendish, elaborando uma definição operativa de elemento e, consequentemente, também de substância química. Lavoisier conhecia os trabalhos de Hales, portanto sabia que algumas substâncias químicas podiam conter gases e desprendê-los (LEICESTER, 1967). Ele também conhecia os trabalhos de todos os seus antecessores e isto fez com que visse a possibilidade de que os gases poderiam se combinar com outros compostos ou se desprenderem a partir de reações químicas. Em 1778, Lavoisier publicou um trabalho no qual dizia que o ar era composto por dois fluidos (semelhante ao trabalho de Scheele, publicado em 1777), um que combinava com os metais e outro o qual chamou de "metífico". Em dezembro de 1774 Lavoisier já pensava que o ar se combinava com os metais durante o processo de calcinação (PARTINGTON, 1989). Os experimentos de Lavoisier só vieram reforçar a ideia de que o ar não era uma substância em si, mas formada a partir de diversos compostos. Isso culminou com as definições formais de elemento e substância que se encontram hoje em livros didáticos de Química. Lavoisier (1789) criticava a teoria filosófica dos quatro elementos, fazendo com que ele mesmo fornecesse uma definição para o conceito de elemento químico. Assim, o químico francês afirma que elemento (ou princípio) é o último termo no qual se possa analisar. Aquelas substâncias que ainda não pode decompor por nenhum meio, são elementos. Logo, como se demonstrava empiricamente na época, o ar e a água não poderiam ser substâncias elementares.

$\mathrm{Na}$ classificação de Lavoisier (1789), na natureza existem os corpos elementares ou substâncias simples, as quais não se podem mais decompor, logo são consideradas elementos. Percebe-se que a substância química é considerada como algo manipulável. As concepções de Lavoisier apresentam uma a ideia de substância simples como sinônimo de elemento químico. A 
partir dessa noção, várias propriedades dos elementos que são conhecidas hoje, tais como temperaturas de fusão e ebulição, foram identificadas a partir da manipulação das substâncias simples. Essa relação entre substância simples e elemento sofreu uma reestruturação no final do século XIX com os estudos de Dmitri Ivanovich Mendeleev (1834-1907), o qual, em suas pesquisas, atribuía ao átomo o status de elemento químico (BENSAUDE-VINCENT; STENGERS, 1992).

No século XX, o conceito ganha uma forma abstrata, em que a existência concreta das substâncias é relativizada. Essa relativização se dá pelo fato de que na natureza não existem substâncias na sua forma pura, sendo a pureza alcançada a partir de diversos processos de purificação aplicados em laboratórios e na síntese de novos materiais, como os nanotubos de carbono e outros materiais nanométricos. Assim, o que se manipula e o que está disponível na natureza são misturas. $\mathrm{O}$ conceito de substância se torna um modelo apenas aplicável dentro do contexto científico, mas que não explica o comportamento dos materiais no mundo real. A água, por exemplo, com temperatura de ebulição de $100^{\circ} \mathrm{C}$ só é possível ser identificada se uma amostra tiver $100 \%$ pura e o sistema se apresentar sob uma pressão de $1 \mathrm{~atm}$, não traduzindo um comportamento real da substância água encontrada na Natureza. É nesse contexto que a visão relacional começa a ser estruturada.

\section{$O$ conceito de substância química no século $X X$ : visão relacional}

Segundo Silva e Amaral (2013), a ideia da substância relacional se dá a partir da concepção de que na natureza não se encontram substâncias isoladas que não interajam com o seu meio. A interação dos materiais com o ambiente faz com que a matéria nunca seja a mesma, mas se apresente em constante transformação, alcançando certos momentos de estabilidade, se comportando como um constante devir (BACHELARD, 1984). Este devir se dá através das trocas energéticas entre a matéria e o ambiente, fazendo com que as moléculas das substâncias constantemente mudem sua forma e a substância em si apresente algumas propriedades que dependam dessas interações com o ambiente. Tal noção faz com que se perceba a estreita relação entre a matéria e a energia.

\section{Relação entre matéria e energia}

Brody e Brody (2006) afirmam que, a partir dos estudos no campo da radioatividade, vários fenômenos começaram a ser explicados, tomando por bases os conceitos de fusão e fissão nuclear. Segundo os autores, a descoberta de Becquerel da emanação espontânea de energia de materiais radioativos, em 1896, forneceu a primeira pista para a imensa energia do Sol (a partir da fusão de núcleos de hidrogênio para formação de núcleos de hélio). Porém, somente 10 anos depois quando Einstein apresentou sua fórmula " $E=\mathrm{mc}^{2}$ " é que se compreendeu a relação entre matéria e energia (BRODY; BRODY, 2006).

Hawking (2001) afirma que massa e energia são equivalentes, conforme a equação de Einstein. Entre as consequências da interpretação desta fórmula estava a percepção de que "se o núcleo de um átomo de urânio se fissionar em dois núcleos com massa ligeiramente menor, uma tremenda quantidade de energia será liberada" (HAWKING, 2001, p. 12). Segundo o físico inglês, a energia liberada é referente à diferença da massa total do núcleo e a soma das massas 
individuais de cada próton e nêutron. Essa energia mantém o núcleo unido e pode ser calculada pela relação de Einstein: energia de ligação nuclear $=\Delta \mathrm{mc}^{2}$, em que $\Delta \mathrm{m}$ é a diferença entre a massa do núcleo e a soma das massas individuais dos prótons e nêutrons.

Considerando-se a relação estreita entre matéria e energia, é possível ver a substância química como algo que está sempre variando, sem apresentar uma entidade molecular estável e fixa. Um exemplo disso são as conformações de algumas moléculas orgânicas. Moléculas orgânicas com grupos ligados apenas por ligações sigma $(\sigma)$ podem sofrer rotações em torno do eixo da ligação, dando origem aos vários confôrmeros (SOLOMONS; FRYHLE, 2005). Cada confôrmero representa a mesma molécula, porém com uma estrutura diferente. Fazendo a análise conformacional do butano, por exemplo, observam-se sete conformações (Figura 1). O gráfico abaixo mostra a relação entre a energia potencial da molécula e o ângulo diedro das diferentes conformações. De acordo com a Figura 1, a conformação mais estável, ou seja, encontrada com maior frequência na substância butano, é a de número IV (estrelada-anti), devido a sua baixa energia.

Figura 1. Análise conformacional do butano

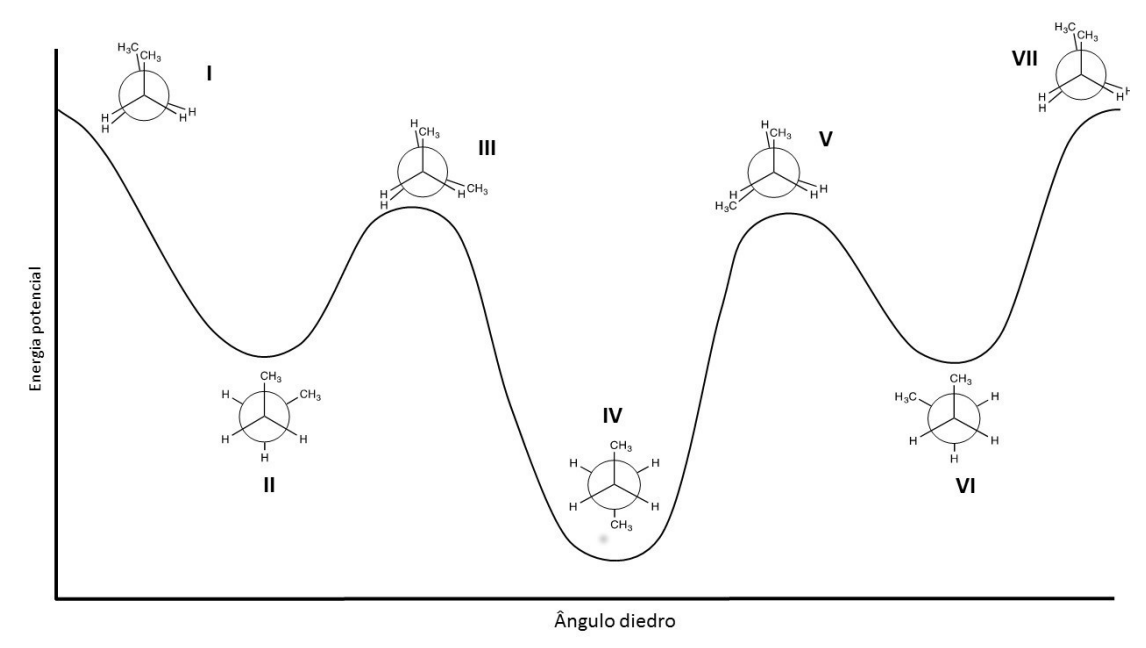

I - Eclipsada; II - Estrelada-gauche; III - Eclipsada; IV - Estrelada-anti; V - Eclipsada; VI - Estrelada-gauche; VII - Eclipsada.

Fonte: elaborada pelo autor.

Na Figura 1, é possível observar diferenças de energia potencial entre uma conformação e outra. Essa energia é considerada uma barreira de rotação, pois é a energia necessária para a molécula passar de uma conformação à outra. Assim, considerando um sistema com a substância butano, pode-se dizer que durante a maior parte do tempo as moléculas se apresentarão na conformação IV (estrelada-anti), sendo esta a de mais baixa energia (mais estável). Porém, todas as moléculas estarão se alternando entre todas as conformações. 
Com isso, pode-se afirmar que a disposição e conformação das moléculas de uma substância estão se alternando devido a fatores energéticos. Isso terá uma influência direta na representação das substâncias. Ao se pensar na substância água, por exemplo, dentro da visão clássica, representa-se por várias moléculas “ $\mathrm{H}_{2} \mathrm{O}$ ”, em sua forma trigonal, estática e sem interagir com o meio. Na visão relacional acerca das substâncias químicas, vê-se a substância água formada por moléculas que estão se auto ionizando constantemente e com seus movimentos rotacionais e vibracionais. É neste sentido que Bachelard (1984) afirma que a substância é como o devir, o qual se apresenta como uma espécie de diálogo entre a matéria e a energia. Segundo o autor, as trocas energéticas determinam modificações materiais e as modificações materiais condicionam trocas energéticas.

\section{As propriedades relacionais}

As substâncias químicas, a partir do século XX, também começam a ser compreendidas a partir de observação de algumas propriedades relacionais. Segundo Mortimer (1997), a aplicação da mecânica quântica à química resulta num conceito não-clássico de molécula, podendo-se dizer a mesma coisa em relação ao conceito de substância química. Diante disso, o autor destaca a natureza relacional de muitas propriedades químicas, que "nos obriga a pensar essas propriedades como resultantes das interações entre moléculas e não como dependentes unicamente da composição e da geometria característica de cada molécula” (MORTIMER, 1997, p. 201). Ou seja, diante dessa ótica, analisa-se as propriedades das substâncias químicas como dependentes das relações entre as substâncias entre si, a natureza das espécies químicas envolvidas e o meio em que ela está inserida. Oliveira (1995, p. 09), por exemplo, afirma que "a acidez de um ácido só tem sentido químico se mencionamos o solvente. Não existem ácidos por si, mas algo é ácido em relação a alguma outra coisa”. Isso implica dizer que o ácido clorídrico, por exemplo, só apresenta sua característica ácida em solução aquosa, mas não em sua forma gasosa (cloreto de hidrogênio). Outro exemplo é quando se analisa o poder oxidante e redutor dos elementos químicos. Só se pode falar no zinco com a propriedade redutora se ele interagir com outra espécie química de natureza oxidante, como o cobre (em sua forma iônica), por exemplo. Essa interação resulta na reação química representada pela equação $\mathrm{Zn}(\mathrm{s})+\mathrm{Cu}^{2+}(\mathrm{aq})$ $\rightarrow \mathrm{Zn}^{2+}(\mathrm{aq})+\mathrm{Cu}(\mathrm{s})$. Já diante do lítio, que pode atuar como agente redutor em determinadas situações, o zinco, em sua forma iônica, irá se comportar como oxidante. A espécie química com a qual o zinco irá reagir determinará a propriedade oxidante ou redutora do metal. Nesse caso, algumas propriedades relacionais vão depender não só do meio, mas também da própria natureza das substâncias. Assim, Oliveira (1995) coloca que, de modo geral, pode-se dizer que a substância não é nada em si mesma e que as características que lhes são atribuídas se constituem em produto de um jogo relacional. Ou seja, a substância não é, mas ela se torna (constantemente está se tornando). E algumas propriedades não pertencem às substâncias, mas emergem a partir deste jogo relacional.

Quando se fala que substâncias puras possuem temperatura de ebulição bem definida, por exemplo, se faz uma aproximação, visto que essa propriedade, bem definida, só é alcançada em determinadas condições de pressão. Em diferentes partes do globo terrestre, um recipiente com água, no seu maior grau possível de pureza, irá apresentar diferentes temperaturas de ebulição, por causa das variações de pressão que dependem da altitude do lugar em que a água irá 
ferver. Ou seja, neste caso, são as condições do ambiente que irão determinar a emergência da propriedade. Por convenção, adotou-se a pressão de $1 \mathrm{~atm}(760 \mathrm{mmHg})$ como condição padrão para determinação das propriedades físicas, como a temperatura de ebulição.

Oliveira (1995) levanta outras propriedades que, na visão clássica da Química, são consideradas como bem definidas, porém devem ser consideradas como relacionais:

- Eletronegatividade: segundo o autor, “a eletronegatividade não existe por si mesma enquanto propriedade elementar, mas é produzida na relação entre os átomos dos elementos quando estes se ligam" (p. 10);

- Valência: considerada, comumente na sala de aula e nos livros didáticos, como uma propriedade elementar das substâncias, mas que, na verdade, dependerá das relações entre átomos e/ou moléculas de diferentes espécies químicas.

$\mathrm{Na}$ Química Orgânica também é possível observar a existência de propriedades relacionais. $\mathrm{Na}$ estereoquímica, por exemplo, pode-se ter uma mesma substância formada por moléculas enantiômeras, as quais não são superponíveis uma na outra. Com base nesta informação, poderíamos dizer que os enantiômeros são compostos diferentes. Porém, Solomons e Fryhle (2005, p. 195) afirmam que os enantiômeros apresentam algumas propriedades semelhantes, tais como temperaturas de fusão e ebulição idênticos, índice de refração e solubilidade em solventes comuns. Contudo, tais comportamentos e propriedades semelhantes entre enantiômeros não são uma regra. Um exemplo disso são as diferentes velocidades de reação que enantiômeros apresentam, resultando em diferentes dinâmicas de reação, sobretudo quando se passa num organismo vivo. Em meados do século XX, no Brasil, houve problemas causados pelo enantiômero ( $\mathrm{S}$ ) da Talidomida, fazendo com que bebês nascessem com má formação dos membros superiores e inferiores. Este problema se deu a partir do uso da Talidomida (sendo vendida uma mistura racêmica dos enantiômeros R e S) consumida com fins analgésicos. Enquanto a propriedade analgésica é atribuída ao enantiômero R, não se sabia que o enantiômero $S$ era capaz de causar má formação de bebês durante a gestação (COELHO, 2001). Ou seja, os enantiômeros R e S da Talidomida apresentam diferentes dinâmicas de reação no meio vivo, frente às especificidades dessas espécies químicas.

Por fim, Mortimer (1997) ratifica a ideia de propriedades relacionais mostrando que várias propriedades que comumente são consideradas como elementares e bem definidas, na verdade, emergem no jogo relacional citado por Oliveira (1995), tais como: acidez e basicidade, comportamento redox e efeitos de solventes em reações. Essas propriedades dependem da interação entre moléculas e não unicamente da estrutura de uma espécie isolada. Por exemplo, os ácidos sulfúrico e clorídrico podem se comportar como bases quando em presença de poderosos doadores de prótons, como os superácidos. Nesses últimos, ácidos fracos como HF e $\mathrm{SbF}_{5}$ podem se transformar num ácido muito mais forte apenas sendo misturados. Também a energia de processos químicos só pode ser entendida em termos relacionais, pois depende da quebra e da formação de ligações (MORTIMER, 1997).

\section{Considerações finais}

A discussão apresentada mostra como o conceito de substância apresenta diversos modos de pensar, os quais emergiram a partir de várias formas de falar ao longo da história da Ciência. A evolução do conhecimento de substância não obedece uma linearidade, sendo possível 
observar modos de pensar diferentes coexistindo em um mesmo período e contexto histórico. Os diversos modos de pensar emergiram de forma simultânea em várias épocas e coexistem hoje, estando dispersos entre concepções informais/alternativas e científicas discutidas em sala de aula, como apontam Silva e Amaral (2013).

Além disso, não se pode afirmar que houve a predominância de alguns modos de pensar em determinados períodos históricos. Dessa forma, foi possível observar que concepções generalistas, por exemplo, estiveram dispersas em várias épocas do desenvolvimento histórico, além de serem encontradas na atualidade, principalmente em contextos e situações do senso comum, como outros modos de pensar (SILVA; AMARAL, 2013).

Admitir tal convívio entre modos de pensar, significa compreender que a visão relacional do conceito de substância química, objeto de estudo deste artigo, não possui uma supremacia em relação às outras concepções que são encontradas nas outras zonas do perfil conceitual de substância. Diante de determinadas situações e contextos, algumas ideias terão um valor pragmático maior do que a visão relacional e, diante disso, nem sempre será necessário admitir, por exemplo, que algumas propriedades das substâncias são relacionais. Quando se analisa o aumento da eletronegatividade ou a geometria da molécula da água, é necessário considerar a substância e suas moléculas constituintes como entes isolados de qualquer interferência, para que se possa determinar certos parâmetros de comportamento e defini-los como padrão. Em determinadas situações, principalmente no Ensino Médio, para fins de cálculo estequiométricos, considera-se que todas as substâncias envolvidas apresentam pureza de $100 \%$, mesmo que a situação trate de uma reação que ocorre na natureza, onde não se encontram substâncias puras isoladas. Ou seja, o que vai valer é o valor pragmático que cada sujeito irá atribuir aos modos de pensar em determinadas situações (MORTIMER; EL-HANI, 2014).

Isso não significa que se deve considerar um pensamento relativista ao se analisar o uso de modos de pensar um conceito científico, caindo na falácia do "tudo vale". Ao contrário, advoga-se que é necessário que o sujeito tenha consciência do uso desses diversos modos de pensar para que os utilize em contextos e situações adequadas. Dessa forma, ratificamos a importância, apontada no início deste artigo, de que a visão relacional do conceito de substância seja discutida em cursos de nível superior de Química, principalmente nas licenciaturas, as quais preparam professores que irão atuar diretamente no Ensino Médio. A falta da discussão dos diversos modos de pensar o conceito de substância, incluindo a visão relacional, pode fazer com que o sujeito, sem ter consciência da pluralidade de concepções, faça uso de determinadas ideias em contextos inadequados, gerando problemas de aprendizagem. $\mathrm{O}$ aluno, por exemplo, por falta da discussão sobre a visão relacional, pode imaginar que a substância água, em sua forma pura, é encontrada na natureza, sendo esta uma concepção informal/alternativa comumente encontrada entre alunos do Ensino Médio (JOHNSON, 2000, 2002).

Métodos de ensino baseados na teoria do perfil conceitual (MORTIMER; EL-HANI, 2014), que permitam que o aluno tenha consciência dos diversos modos de pensar, ainda são escassos na literatura e na prática escolar. Diante disso, enfatiza-se a importância do desenvolvimento de pesquisas que busquem modos que permitam com que o aluno de Química, em qualquer nível de ensino, possa ter consciência da heterogeneidade de pensamento de alguns conceitos, aplicando cada modo de pensar em contextos adequados. 
Diversos modos de pensar o conceito de substância química ...

\section{Referências}

AMARAL, E. M. R.; MORTIMER, E. F. Uma proposta de perfil conceitual para o conceito de calor. Revista Brasileira de Pesquisa em Educação em Ciências, Belo Horizonte, v. 1, n. 3, p. 1-16, 2001.

ARAÚJO, D. X.; SILVA, R. R.; TUNES E. O conceito de substância química apreendido por alunos do ensino médio. Química Nova, São Paulo, v. 1, n. 18, p. 80-90. 1994.

ARISTÓTELES. Física. Planeta de Agostini. [S.1.]: Editora Gredos, 1995. Disponível em: $<$ http://bz.otsoa.net/Libros\%20de\%20Divulgacion\%20Cientifica/Historicos\%20de \%20 Ciencia/Aristoteles\%20-\%20Fisica.pdf>. Acesso em: 18 nov. 2016.

Metafísica. São Paulo: Edipro, 2006.

ATKINS, P. W.; JONES, L. Princípios de química: questionando a vida moderna e o meio ambiente. 5. ed. Porto Alegre: Bookman, 2012.

ATKINS, P.; DE PAULA, J. Atkins físico-química. 8. ed. Rio de Janeiro: LTC. 2006.

BACHELARD, G. A filosofia do não. 2. ed. São Paulo: Abril Cultural, 1984. (Coleção Os pensadores).

A formação do espírito científico. Rio de Janeiro: Contraponto, 1996.

BENSAUDE-VINCENT, B. B.; STENGERS, I. História da química. Lisboa: Editora Piaget, 1992.

BRODY, D. E.; BRODY, A. R. As sete maiores descobertas científicas da história. 7.ed. São Paulo: Companhia das Letras, 2006.

COELHO, F. A. S. Fármacos e quiralidade. Química Nova na Escola, São Paulo, n. 3, p. 23-32, 2001.

DINIZ JUNIOR, A. I.; SILVA, J. R. R. T.; AMARAL, E. M. R. Zonas do perfil conceitual de calor que emergem na fala de professores de química. Química Nova na Escola, São Paulo, v. 37, número especial 1, p. 55-67, 2015.

GOLDFARB, A. M. Da alquimia à química. São Paulo: Landy, 2001.

GORRI, A. P.; FILHO, U., S. Representação de temas científicos em pintura do século XVIII: um estudo interdisciplinar entre química, história e arte. Química Nova na Escola, São Paulo, v. 31, n. 3, p. 184-189, 2009.

HAWKING, S. O universo numa casca de noz. São Paulo: ARX, 2001.

JOHNSON, P. Children's understanding of substances, part 1: recognizing chemical change. International Journal of Science Education, Abingdon, v. 22, n. 7, p. 719-737, 2000.

JOHNSON, P. Children's understanding of substances, part 2: explaining chemical change. International Journal of Science Education, Abingdon, v. 24, n. 10, p. 1037-1054, 2002.

LAVOISIER, A. L. Traité élémentaire de chimie, 1789. Disponível em: < http://www. labirintoermetico.com/01Alchimia/Lavoisier_A_L_de_Traite_elementaire_de_chimie(1789). pdf > Acesso em: 18 nov. 2016. 
LEICESTER, H. M. Panorama historico de la química. Madrid: Alhambra, 1967.

MAAR, J.H. Pequena história da química: primeira parte dos primórdios a Lavoisier. Florianópolis: Papa-livro, 1999.

MORTIMER, E. F.; EL-HANI, C. N. A theory of teaching and learning scientific concepts series: contemporary trends and issues in science education. Dordrecht: Springer, 2014.

MORTIMER, E. F. Para além das fronteiras da química: relações entre filosofia, psicologia e ensino de química. Química Nova, São Paulo, v. 20, n. 2, 200-207, 1997.

OKI, M. C. M. O conceito de elemento: da antiguidade a modernidade. Química Nova na Escola, São Paulo, n. 16, 2002.

OLIVEIRA, R. J. O mito da substância. Química Nova na Escola, São Paulo, v. 1, n 1, p. 8-11, 1995.

PARTINGTON, J. R. A short history of chemistry. $3^{\text {rd }}$. ed. New York: Dover, 1989.

PAOLLONI, L. Química e mecânica quântica: relação entre a estrutura lógica da química e a realidade molecular. Química Nova, São Paulo, v. 3, n. 4, p. 164-171, 1980.

POPHRISTIC, V.; GOODMAN, L. Hyperconjugation not steric repulsion leads to the staggered structure of ethane. Nature, London, n. 411, p. 565-568, 2001.

POZO, J. I.; CRESPO, M. A. G. Aprender y enseñar ciencia. Madrid: Morata, 1998.

SIMÕES NETO, J. E. Uma proposta para o perfil conceitual de energia em contextos de ensino da fisica e da química. 2016. 248 f. Tese (Doutorado em Ensino de Ciências) Universidade Federal Rural de Pernambuco, Recife, 2016.

SILVEIRA, M. P. Uma análise epistemológica do conceito de substância em livros didáticos de $5^{a}$ a $8^{\text {a }}$. séries do ensino fundamental. 2003. 144f. Dissertação (Mestrado) Faculdade de Educação, Universidade de São Paulo, São Paulo, 2003.

SILVA, J. R. R. T. Um perfil conceitual para o conceito de substância. 2011. 183f. Dissertação (Mestrado) - Universidade Federal Rural de Pernambuco, Recife, 2011.

SILVA, J. R. R. T.; AMARAL, E. M. R. Proposta de um perfil conceitual para substância. Revista Brasileira de Pesquisa em Educação em Ciências, Rio de Janeiro, v. 13, n. 3 , 2013.

SOLOMONS, T. W. G.; FRYHLE, C. B. Química orgânica. 8. ed. São Paulo: LTC, 2005. v. 1. VOGELEZANG, M. J. Development of the concept 'chemical substance': some thoughts and arguments. International Journal of Science Education, Abingdon, v. 9, n. 5, p. 519-528, 1987.

Artigo recebido em 27/08/2016. Aceito em 09/01/2017.

Endereço para contato: Universidade Federal de Pernambuco, Centro Acadêmico do Agreste, Rodovia BR-104, Km 59, s/n, CEP 55002-970, Nova Caruaru, Caruaru, PE, Brasil. 